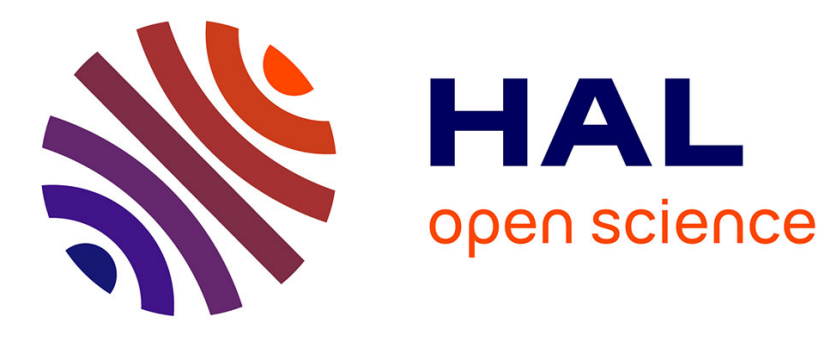

\title{
Recent advances in topical applications for a new anti-acing drug
}

Bénédicte Cantecor, Marie-Pierre Savelli, Gilberte Marti-Mestres, Vincent Bonniol, Mohamed A. Mostefa Side Larbi, Philippe Piccerelle

\section{- To cite this version:}

Bénédicte Cantecor, Marie-Pierre Savelli, Gilberte Marti-Mestres, Vincent Bonniol, Mohamed A. Mostefa Side Larbi, et al.. Recent advances in topical applications for a new anti-acing drug. Robert Chilcott, Keith R. Brain. Advances in Dermatological Sciences, Royal Society of Chemistry, pp.265281, 2013, 978-1-84973-398-4. 10.1039/9781849734639-00265 . hal-01628382

\section{HAL Id: hal-01628382 \\ https://hal-amu.archives-ouvertes.fr/hal-01628382}

Submitted on 13 Nov 2017

HAL is a multi-disciplinary open access archive for the deposit and dissemination of scientific research documents, whether they are published or not. The documents may come from teaching and research institutions in France or abroad, or from public or private research centers.
L'archive ouverte pluridisciplinaire HAL, est destinée au dépôt et à la diffusion de documents scientifiques de niveau recherche, publiés ou non, émanant des établissements d'enseignement et de recherche français ou étrangers, des laboratoires publics ou privés. 

DRUG

B Cantecor ${ }^{1,4}$, M P Savelli ${ }^{1}$, G Marti-Mestres ${ }^{2}$, V Bonniol ${ }^{3,4}$, M A Mostefa Side Larbi ${ }^{1,3,4}$ and P Piccerelle ${ }^{1,5}$

${ }^{1}$ Biopharmacy Laboratory, Faculty of Pharmacy, Aix-Marseille University, France. ${ }^{2}$ Faculty of Pharmacy, University of Montpellier I, France. ${ }^{3}$ Faculty of Medicine, AixMarseille University, France. ${ }^{4}$ Prenyl Bio, Marseille, France. ${ }^{5}$ IMBE, Aix-Marseille University, France.

\section{INTRODUCTION}

The human life span has more than doubled over the last two centuries. With this increase in life expectancy, a significant segment of the aging population will seek to improve their quality of life including the ability to preserve a more youthful appearance for as long as possible [1]. Skin is notably sensitive to aging because it is affected by both intrinsic (genetically determined) and extrinsic (sun radiation, stress, pollution, etc.) processes. In response to consumer demand, numerous laboratories have developed new topical antiaging formulas labeled as "innovative" but containing common active ingredients (alphahydroxy acids, antioxidants, depigmenting agents, etc.) which represent nothing revolutionary because they have been used for many years to reduce signs of ageing [2-4].

Progeria, also known as Hutchinson-Gilford Progeria Syndrome (HGPS), is one of 7,000 identified rare diseases [5]. Progeria is characterised by premature and accelerated aging. The first signs of the disease appear in the first 12-18 months of life and are characterised by a break in the growth curve. The average age of death is 13.5 years, often caused by myocardial infarction or stroke. Progeria children have a characteristic phenotype including very thin skin, superficial veins, pinched nose, alopecia and microretrognathia (abnormal development of the face). Progeria children exhibit severe generalised atherosclerosis and suffer from a significant reduction in bone density and lipoatrophy [5, 6]. The mutation responsible for progeria, found in the $L M N A$ gene encoding lamin A and C, was identified independently in 2003 by French and US researchers [7, 8]. Three different genetic diseases resulting in accelerated aging, i.e., HGPS, restrictive dermopathy and mandibuloacral dysplasia, have been shown to exhibit the same pathophysiological mechanism [9]. Mutation of either the LMNA gene or the gene encoding the protease involved in the cleavage of the last $15 \mathrm{C}$-terminal amino acids of the lamin A precursor (FACE1/ZMPSTE24) leads to the presence of farnesylated progerin, which is anchored to membranes through its farnesyl anchor. The phenomenon results in the accumulation of farnesylated progerin in the nuclear lamina, inducing characteristic changes in nuclear shape and size and resulting in a decrease of "soluble" mature lamin A in the remaining nucleoplasm. This abnormality in the composition of the nuclear matrix causes several disorders in nuclear genome activity that trigger cell aging, including DNA repair and 
RNA transcription and maturation. Without $L M N A$ mutations, progerin is also produced by cells in aged subjects, due to age-related dysfunction of mRNA splicing machinery [10]. Finally, the expression of progerin by stem cells derived from adult tissues belonging to either epidermal [11] or mesenchymal lineages [12] leads to rapid exhaustion of the stem cell pool: a further pro-aging event.

Research on progeria provides an alternative source of active ingredients. The combination of two drugs, a statin and an aminobisphosphonate, decreases the accumulation and/or persistence of prenylated (farnesyl or a geranylgeranylated) nuclear proteins that are responsible for cell aging in progeria patients. The same combination also corrects several disorders exhibited in a mouse model reproducing human progeria and increases the life span of these mice [13]. Among the available statins and aminobisphosphonates on the market, we selected a combination of sodium pravastatin (PRA) and sodium alendronate (ALN) on the basis of screening results obtained with cultured fibroblast cells [14]. This drug pair improved the mitotic index of cells significantly and is widely available.

The purpose of the present investigation was to study the transdermal diffusion of the drug pair from a topical vehicle to assess its skin bioavailability for future applications. The active ingredients must penetrate the stratum corneum (SC) and diffuse in sufficient concentrations to the intended target in the skin over a consistent time course [15]. It is well known that choice of vehicle strongly influences skin absorption $[16,17]$ and so the in vitro study was performed with Franz static diffusion cells [18] using an oil-in-water $(\mathrm{O} / \mathrm{W})$ emulsion vehicle directly therein, fulfilling the necessary criteria for collecting relevant cosmetic information. Dermal kinetics were determined using porcine skin following the guidelines of the Scientific Committee on Consumer Safety (SCCS) [19] and the Organisation for Economic Co-operation and Development Guideline TG 428 [20]. Pig (ear) skin resembles human skin morphologically and functionally, and drug permeation rates appear to be similar in pig and human skin [21].

\section{MATERIALS AND METHODS}

\section{Test product formulation and characterisation}

The following chemical products were used for donor formulation: purified water $(10.0 \pm$ $5.0 \mu \mathrm{S}$, Elix Advantage 3, Millipore, France), sodium alendronate trihydrate ( $\mathrm{Ph}$. Eur. Quality; Cadila Pharmaceutical Limited, India), sodium pravastatin (Ph. Eur. Quality; Hisun, China), isononyl isononanoate (Seppic, France), caprylic/capric triglyceride (Evonik Goldschmidt GmbH, Germany), glycerin (Spiga Nord, Italy), arachidyl alcohol and behenyl alcohol and arachidyl glucoside (Seppic, France), PEG-100 stearate and glyceryl stearate (Seppic, France), polyacrylate-13 and polyisobutene and polysorbate 20 (Seppic, France), glycol palmitate (Seppic, France), caprylyl glycol (Schülke, France), ethylhexylglycerin (Schülke, France), tocopheryl acetate (DSM, Switzerland), dye (Sensient Cosmetic Technologies, France), methyisothiazolinone (Schülke, France) and sodium hydroxide (Cooper, France).

Differential Scanning Calorimetry (DSC 131, Setaram Instrumentation, France) was used to characterise the potential reactivity of active ingredients. Samples were prepared by mixing the drugs $(50 / 50, \mathrm{w} / \mathrm{w})$ and heating the mixtures from $25^{\circ} \mathrm{C}$ to $200{ }^{\circ} \mathrm{C}$ with a ramp 
of $10^{\circ} \mathrm{C} \mathrm{min}{ }^{-1}$. The samples were sealed in $30 \mu \mathrm{l}$ aluminum pans and the experiments were performed in ambient air.

Preliminary results obtained on young and old fibroblast cultures have demonstrated a synergistic effect for PRA and ALN on fibroblast mitotic index [14]. This mitosisactivating effect was induced by $1 \mu \mathrm{M}$ of each drug, i.e., $4.465 \times 10^{-5} \%$ (w/w) of PRA and $3.251 \times 10^{-5} \%(\mathrm{w} / \mathrm{w})$ of ALN. We therefore chose to study a mixture with equimolar equivalents of PRA and ALN. As the most effective dose on fibroblasts was very low (1 $\mu \mathrm{M})$, the starting dose of PRA was set at a theoretical concentration of $0.5 \%(\mathrm{w} / \mathrm{w})$ in the donor formulation, and ALN was set at a theoretical amount of $0.375 \%(\mathrm{w} / \mathrm{w})$. The formulation was an $\mathrm{O} / \mathrm{W}$ emulsion prepared by stepwise addition of the inner oily phase to the aqueous phase at $85{ }^{\circ} \mathrm{C}$. The addition of oil was performed under rotor stator agitation at $1700 \mathrm{rpm}$ (Turbotest, VMI Rayneri, France). An Eclipse E600 optical microscope (Nikon) and a PC running the Lucia G version 4.8 software image analyser (Roucaire, France) were used to determine the mean globule size. Viscosities were determined using a rotating viscometer (Brookfield DV-II+ pro, USA). The measurements were conducted at $25{ }^{\circ} \mathrm{C}$ with a No. 4 spindle at $6 \mathrm{rpm}$. Sample $\mathrm{pH}$ was directly measured without dilution with a Cyberscan pH $510 \mathrm{pH}$ meter (Eutech Instrument, Netherlands) at $25^{\circ} \mathrm{C}$. Emulsion density was measured at $20{ }^{\circ} \mathrm{C}$ using a pycnometer (Erichsen, France) with a $50 \mathrm{~mL}$ sample cell.

To visualise emulsion stability, a water-soluble blue colorant (methylene blue) was added to the formulation which was then centrifuged at $4,400 \mathrm{rpm}$ for 30 minutes at $25{ }^{\circ} \mathrm{C}$ (using a 5702 RH Centrifuge, Eppendorf, Germany). Sample homogeneity was visually inspected. The system was considered destabilised when phase separation or coalescence was observed. Emulsion stability was assessed by accelerated aging of the prepared emulsion by measuring physicochemical properties (viscosity, $\mathrm{pH}$, and globules size) during storage of the emulsion in a glass container under shelf-life testing conditions at room temperature for 6 months and under accelerated conditions of 4 and $40{ }^{\circ} \mathrm{C}$ for 6 months or under accelerated conditions of $50{ }^{\circ} \mathrm{C}$ for 3 months (vacuum drying oven, VD23/53/115 WTB Binder, Germany).

\section{Measurement of transdermal delivery}

Static Franz glass diffusion cells (Legallais, France) were used for this investigation. These cells consist of donor and receptor chambers between which a piece of whole porcine skin was positioned. The receptor chamber fluid was physiological serum (Versol $\mathrm{NaCl} 0.9 \%$, Aguettant, France) and $0.1 \mathrm{M}$ sodium citrate (Sigma, France). After an initial visual inspection of the skin, a TM210 tewameter (Courage-Khazaka, Germany) was used to determine transepidermal water loss (TEWL), which reflects skin integrity [22]. The rate of percutaneous penetration and TEWL was greatly increased when the barrier function of the SC was compromised. If the barrier was disrupted, the sample was not used in the study. Skin thickness was measured using a dial thickness gauge (0.01-10 mm; Mitutoyo Ehy 331, Japan).

Skin permeability studies were performed using methods described elsewhere [17, 23, 24]. Porcine ears (three different donors) were obtained from freshly killed animals at a local slaughterhouse (Pézenas, France). After cleaning with cold tap water, full-thickness, nondermatomed skin (approximately $0.9-1.1 \mathrm{~mm}$ ) was removed with a scalpel from the 
cartilage of the dorsal pinnae. Intact skin discs with an internal diameter of $3 \mathrm{~cm}$ were sealed in plastic bags and stored for no more than 6 weeks at $-20{ }^{\circ} \mathrm{C}$ [25]. The skin samples were mounted inside modified Franz diffusion cells [18] in such a way that the dermal side of the skin was exposed to the receptor fluid. The diffusion area was $0.95 \mathrm{~cm}^{2}$. The precise volume of the acceptor compartment (approximately $9 \mathrm{~mL}$ ) was measured for each cell and was included in the calculations. The continuously stirred receptor medium (physiologic serum Versol $\mathrm{NaCl} 0.9 \%$ solution to preserve skin conditions) was maintained at $37 \pm 1$ ${ }^{\circ} \mathrm{C}$ by water circulation (Polystat $\mathrm{CC} 1$, Huber). Under these conditions, the skin disk temperature was $32 \pm 1{ }^{\circ} \mathrm{C}$, which corresponds to the skin surface temperature in vivo (measured with Thermocouple thermometer, ecoScan).

Skin absorption experiments were started by the topical application of $30.1-57.5 \mathrm{mg}$ of test product to the surface of the skin through the donor compartment after which the donor chambers were covered with Parafilm ${ }^{\circledR}$ to minimise evaporation.

After an exposure time of $24 \mathrm{~h}$, the diffusion cells were dismounted, and the skin surface was washed with $10 \mathrm{~mL}$ of $0.1 \mathrm{M}$ sodium citrate, which also served to flush the Parafilm ${ }^{\circledR}$ covering the donor compartment. These $10 \mathrm{~mL}$ were re-used to wash (by passage) the walls of the donor compartment.

Tape stripping was used to separate the superficial layers of the SC [26]. The SC of the treated area was removed by 15 successive tape-stripping steps using D-Squam ${ }^{\mathrm{TM}}(\varphi=14$ $\mathrm{mm}$; Monaderm, Monaco) with a constant pressure $\left(225 \mathrm{~g} \mathrm{~cm}^{-2}\right)$ for $5 \mathrm{~s}$. After eliminating the SC from skin samples via tape stripping, the viable epidermis and dermis samples were chopped into small pieces, and the test substances were extracted with $5 \mathrm{~mL}$ of $0.1 \mathrm{M}$ sodium citrate solution for $24 \mathrm{~h}$ under constant shaking.

A total of eight Franz cells were used for the study. During the Franz test, all cells were subject to application of the test "preparation" with the exception of Cell 1, which was used as a blank cell with no product application, and Cell 8, which received a placebo (a preparation without active substances; vehicle control).

\section{Sample analysis}

All reagents used for chromatography were analytical reagent grade: sodium citrate (Sigma, France), sodium borate decahydrate (Sigma, France), 9-fluorenylmethyl chloroformate (FMOC) (Fluka, France), orthophosphoric acid $85 \%$ (Sigma, France), acetonitrile (Carlo Erba, France), dichloromethane (Carlo Erba, France), methanol (Carlo Erba, France), glacial acetic acid (VWR, France), and triethylamine (Sigma, France). Ultrapure water was obtained from a Direct Q5 water purification system (Millipore, France).

Determination of drug concentrations (PRA and ALN) was determined by two methods according to the analytical substrate (solid or liquid). Solid samples included SC tape strips, epidermis and dermis. Liquid samples included receptor chamber fluid and diffusion cell washing solutions. Solid substrates were extracted with $5 \mathrm{~mL}$ of $0.1 \mathrm{M}$ sodium citrate solution under magnetic stirring for 24 hours. Liquid samples were analysed following filtration $(0.45 \mu \mathrm{m}$ pore, $33 \mathrm{~mm}$ diameter Millipore PVDF filters; Merck Millipore, France). 
Drug analysis was performed by high-performance liquid chromatography (HPLC) using an AN-HPLC-001 and AN-HPLC-004 high-performance liquid chromatography system equipped with a quaternary pump, automatic injector, column oven and an Agilent 1100 or 1200 series detector (Agilent Technologies, France) using a diode array or equivalent and Agilent Chemstation software (Agilent Technologies, France).

Separation of PRA was performed using a $\mathrm{C}_{18}$ column (Agilent Eclipse XDB, $250 \times 4.6$ $\mathrm{mm}, 5 \mu \mathrm{m}$ ) at $25^{\circ} \mathrm{C}$ and detected at $238 \mathrm{~nm}$ with a retention time of $15 \mathrm{~min}$ using a 90/10 phase $\mathrm{A} /$ methanol mobile phase at a flow rate of $1.5 \mathrm{~mL} \mathrm{~min}^{-1}$. The analysis time was 40 min, and $10 \mu \mathrm{L}$ injection volumes were used. Mobile phase A was prepared using a mixture of $450 \mathrm{~mL}$ of methanol, $1 \mathrm{~mL}$ of acetic acid, $1 \mathrm{~mL}$ of triethylamine and $550 \mathrm{~mL}$ of water in 1,000 mL flask. The mobile phase was stirred magnetically for a few minutes and filtered through a $0.45 \mu \mathrm{m}$ membrane filter. The diluent was obtained using a 45/55 (v/v) mixture of methanol and water. PRA standards were prepared by dilution of a PRA stock solution.

Separation of ALN was performed by using a PLRP-S column (Polymer Lab, $150 \times 4.6$ $\mathrm{mm}, 5 \mu \mathrm{m}$ ), at $25^{\circ} \mathrm{C}$. ALN was detected at $266 \mathrm{~nm}$ with a retention time of $5 \mathrm{~min}$ using a $75 / 5 / 20$ phase $\mathrm{A} / \mathrm{methanol} /$ acetonitrile mobile phase at a flow rate of $1.0 \mathrm{~mL} \mathrm{~min}{ }^{-1}$. Analysis times were $30 \mathrm{~min}$ for the assay and $15 \mathrm{~min}$ for the standards, and $20 \mu \mathrm{L}$ injections were used. Mobile phase A consisted of a diluent/sodium phosphate solution adjusted to $\mathrm{pH} 8$ with orthophosphoric acid. The diluent was a $0.1 \mathrm{M}$ sodium citrate solution. Sodium phosphate buffer was obtained by adjusting a $0.1 \mathrm{M}$ sodium phosphate solution to $\mathrm{pH} 8$ with orthophosphoric acid. The tetraborate solution was $0.1 \mathrm{M}$. A derivatisation solution was prepared by dissolving FMOC in acetonitrile to obtain a $0.1 \%$ $\mathrm{w} / \mathrm{v}$ solution. The derivatisation step consisted of adding $1 \mathrm{~mL}$ of a standard or sample solution, $1 \mathrm{~mL}$ of tetraborate solution and $0.8 \mathrm{~mL}$ of derivatisation solution to $10 \mathrm{~mL}$ samples tubes with caps. The tubes were mixed by vortex agitation for 30 seconds and allowed to stand for 30 minutes at ambient temperature. Next, $5 \mathrm{~mL}$ of dichloromethane was added, and the tubes were vortexed for 30 seconds. The tubes were then centrifuged for 10 minutes at 2,000 rpm. The supernatants were transferred to vials after filtration.

The amounts of each drug were quantified by reference to the calibration standards and converted to percentage of applied dose. The "unabsorbed dose" was defined as the amount of drug in the donor compartment and tape strips. "Absorbable dose" was represented by the quantities in the epidermis and dermis. The amount of test compound in the receptor fluid was defined as the "absorbed dose".

\section{RESULTS AND DISCUSSION}

The physicochemical properties of PRA and ALN are listed in Table 1. It is well known that physicochemical criteria influence transdermal bioavailability. Ideal transdermal candidates are characterised by an aqueous solubility greater than $1 \mathrm{mg} \mathrm{mL}^{-1}$, a lipophilicity (log octanol-water partition coefficient) between 1 and 3, a molecular weight less than 500 Daltons (Da), a melting point below $200{ }^{\circ} \mathrm{C}$ and saturated aqueous solution $\mathrm{pH}$ between 5 and 9 [27-30]. 
Table 1 Formulae and physical characteristics of sodium pravastatin (PRA) and sodium alendronate $(A L N) .{ }^{*}$ Values from experimental data. ${ }^{* *} P=$ octanol/water partition coefficient. ${ }^{* * *} K_{p}\left(\mathrm{~m} \mathrm{~s}^{-1}\right)=$ permeability coefficient; $K_{p}$ values were calculated from Potts and Guy's equation [16].

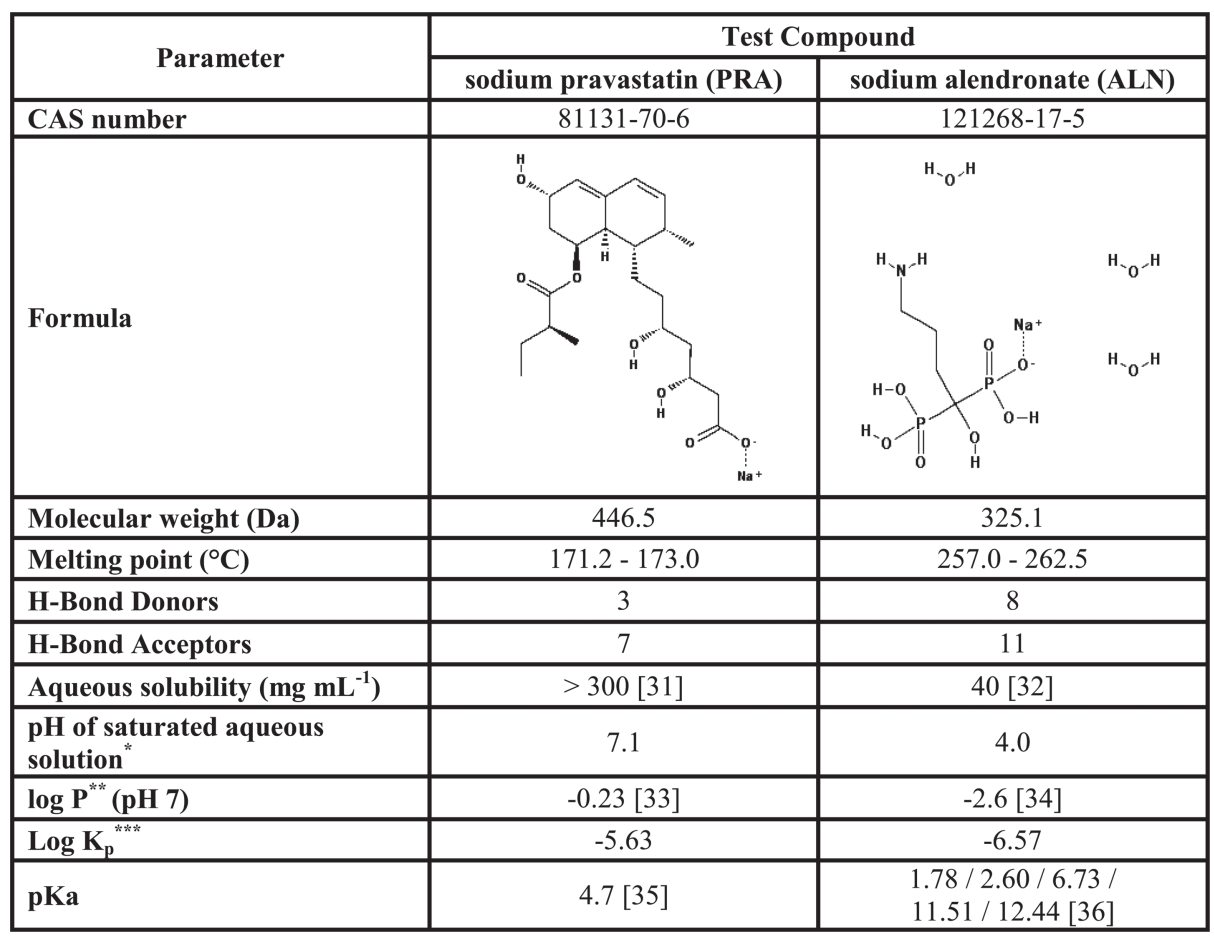

It is difficult to predict the amplitude of skin penetration of the studied drugs from the overall data because only some of the physicochemical parameters are favorable. Molecular weight is one of the main determinants in skin delivery [27, 29]: both drugs are sufficiently small to pass through the stratum corneum. PRA also has a low melting point, suggesting lower intermolecular forces and a higher propensity to cross the skin barrier $[37,38]$. Nevertheless, the marked hydrophilicity (high water solubility, $\log \mathrm{P}<0$ ) may hinder transfer and diffusion into the SC (transdermal drug delivery) and therefore be a limiting factor. Drug mobility is also a function of hydrogen bonding groups and is inversely proportional to the diffusion coefficient $[39,40]$. Molecules with more than four hydrogen bonding groups have very low diffusivity $[38,41]$ and so it was expected that the two active ingredients would have very low diffusivities across the stratum corneum. The diffusion of permeants is also affected by the concentrations of ionised forms generated at different $\mathrm{pH}$ values (see later).

The differential scanning calorimetry (DSC) curve for PRA displays two endothermic peaks at $113{ }^{\circ} \mathrm{C}$ and $151{ }^{\circ} \mathrm{C}$ (Figure 1) which correspond to (a) coordinated and crystal water and (b) melting point, respectively. This result is in good agreement with previous PRA DSC data [42]. 


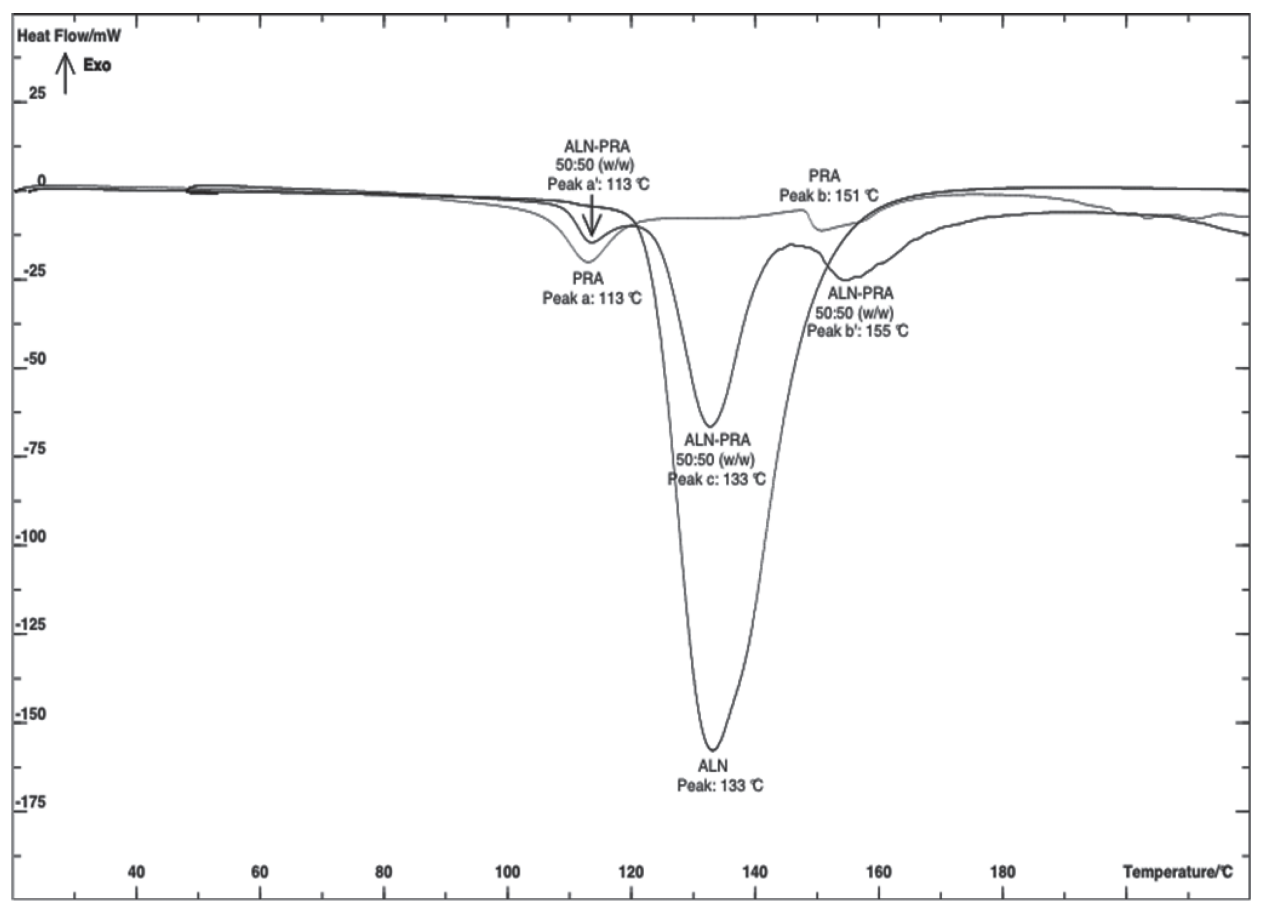

Figure 1 Differential scanning calorimetry curves (DSC) for sodium pravastatin and sodium alendronate.

The DSC curve for ALN indicates an endothermic peak at $133{ }^{\circ} \mathrm{C}$ which corresponds to coordinated and crystal water. The melting point of ALN was not reached because we did not study the behavior of the two drugs beyond the PRA melting point (approximately 172 ${ }^{\circ} \mathrm{C}$ ). The DSC curve of a 50/50 mixture of the two drugs presents the same peaks as those for each separate active ingredient: the active ingredients behave identically to the single components. Thus, we concluded that there was no interaction between the two active ingredients.

Both PRA and ALN are salts of weak acids and strong bases. Dissolution in water leads to dissociation of $\mathrm{Na}^{+}$and the ionised (weak acid) form according to each $\mathrm{pKa}$ and solution $\mathrm{pH}$ (Table 1). The $\mathrm{pKa}$ value of pravastatin is 4.7 and at a $\mathrm{pH}$ equal to the $\mathrm{pKa}, 50 \%$ of the salt exists as the molecular species and $50 \%$ is ionised (Figure 2). Below pH 3, only the molecular species exists; above $\mathrm{pH} 7$, only the ionised species exists. The pKa of PRA (4.7) is close to cutaneous $\mathrm{pH}$ (approximately 5.5) [1]; near this value, small changes in $\mathrm{pH}$ drastically alter the ionic/molecular species ratio. The $\mathrm{pH}$ of the donor formulation ( $\mathrm{pH} 6)$ results in a mixture of $5 \%$ of molecular species coexisting with $95 \%$ ionised species. Therefore, $\mathrm{pH}$ is a critical parameter for the absorption of PRA.

Alendronate (ALN) dissociation as a function of $\mathrm{pH}$ is much more complex. Alendronate has five $\mathrm{pKa}$ values (Table 1) that corresponding to six functional groups that can be ionised: five $\mathrm{H}^{+}$donors and one amino group $\mathrm{H}^{+}$acceptor [36]. As illustrated in Figure 3, in the $\mathrm{pH}$ range of interest (5-7), there are principally two ionised species: $\mathrm{H}_{3} \mathrm{~L}^{-}$and $\mathrm{H}_{2} \mathrm{~L}_{2}^{-}$. At $\mathrm{pH} 6,84 \%$ of the molecules are in the $\mathrm{H}_{3} \mathrm{~L}^{-}$form, and $16 \%$ exist in the $\mathrm{H}_{2} \mathrm{~L}_{2}{ }^{-}$form. 
The ionised species of a drug has a lower permeability coefficient than its respective molecular species. Thus, the free acid or free base should be preferentially used to improve permeation [43]. Pugh and coworkers found that charge and MW are equally important predictors of diffusion [44]. Accordingly, PRA and ALN have pKa values that are not conducive to the efficient spread of drugs through the skin.

The donor formulation was an $\mathrm{O} / \mathrm{W}$ emulsion with a light, non-oily texture that was easy to apply and left no residue after application. These are characteristics that influence consumer acceptance and patient compliance for a cosmeceutical product [45]. The physicochemical characteristics of the $\mathrm{O} / \mathrm{W}$ emulsion were the following: viscosity, 40,000 mPa s (6 rpm; spindle No. 4; $\left.25^{\circ} \mathrm{C}\right)$; pH, $6\left(25^{\circ} \mathrm{C}\right)$; density, $0.99\left(20^{\circ} \mathrm{C}\right)$; and a globule size $<5 \mu \mathrm{m}$. These results are in agreement with data typically reported for this type of formulation. To determine the exact amounts of the active ingredients in the emulsion, the preparation used for this study was analysed by HPLC/UV. The donor formulation contained $0.55 \%(\mathrm{w} / \mathrm{w})$ PRA and $0.39 \%(\mathrm{w} / \mathrm{w})$ ALN. These concentrations were selected for the permeability study.

From the perspective of transdermal delivery, the formulation does not meet the required criteria. The concentration of PRA and ALN are very low, the drugs are highly hydrolysable and easily ionised, and the vehicle is essentially aqueous. Indeed, the SC (constituting the major natural skin barrier) is predominantly lipoidal in nature, implying high lipid solubility for maximal output into the SC. However, water is the most natural penetration enhancer. Water increases the hydration of the SC and so increases the transdermal diffusivity of a variety of chemicals [46]. Moreover, high aqueous solubility is essential for maximal output into the viable epidermis. The ideal penetrant must therefore have two opposing prerequisites (lipophilicity and hydrophilicity) to penetrate the different skin layers effectively [47].

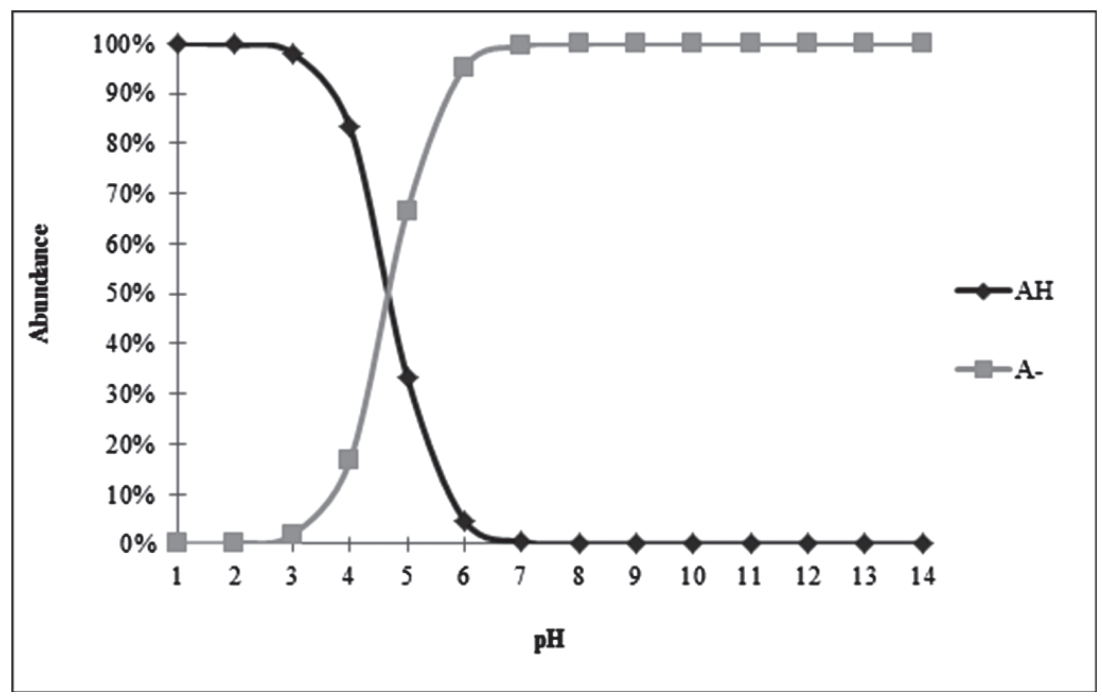

Figure 2 Protonation distribution diagram showing the relative abundances of PRA species [unionised ("AH") and ionised (" $A^{-1}$ ")] at equilibrium as a function of $p H$. 


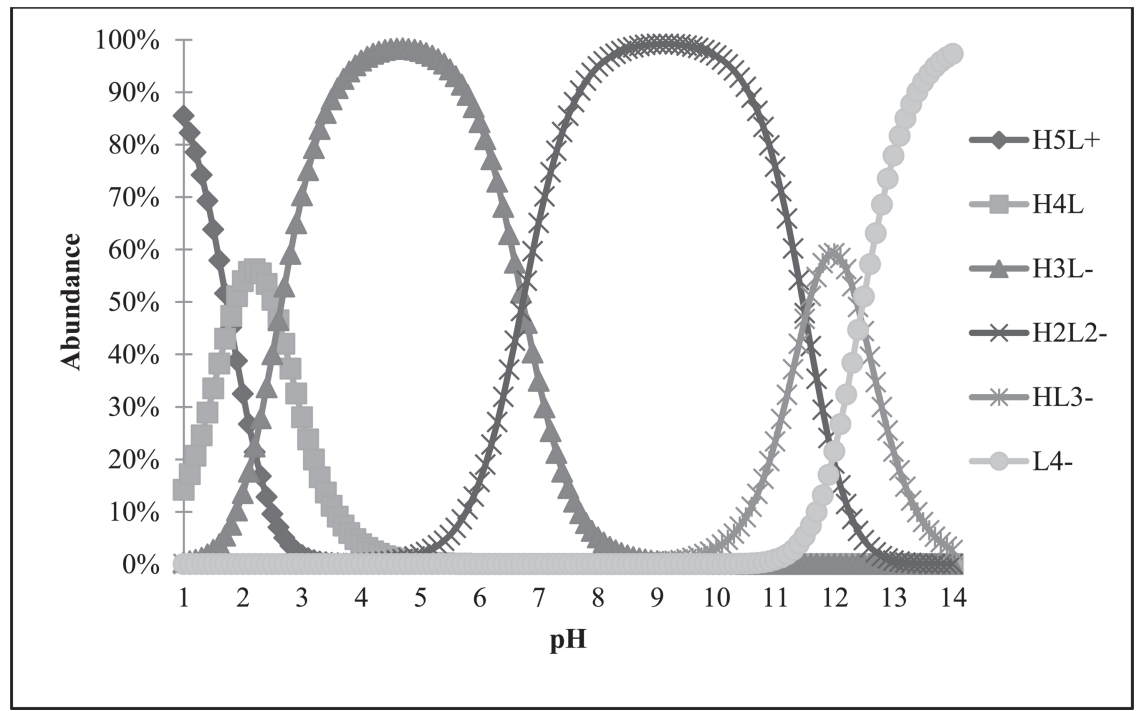

Figure 3 Protonation distribution diagram showing the relative abundances of $A L N$ species [unionised; "H4L" or ionised; " $H 5 L^{+, ", ~ " H 3 L-", ~ " H} 2 L^{2-, "}$ and $H L^{3-, "] ~ v s . ~} p H$ at equilibrium.

Viscosity and $\mathrm{pH}$ of the test formulation were stable at room temperature over the duration of the test period ( 6 months; Figure 4). The donor formulation was stable at $40{ }^{\circ} \mathrm{C}$ over the entire 6 months and at $50^{\circ} \mathrm{C}$ for 3 months. No instability was observed after the centrifuge test $\left(30 \mathrm{~min}\right.$ at $4,400 \mathrm{rpm}$ at $\left.25^{\circ} \mathrm{C}\right)$.

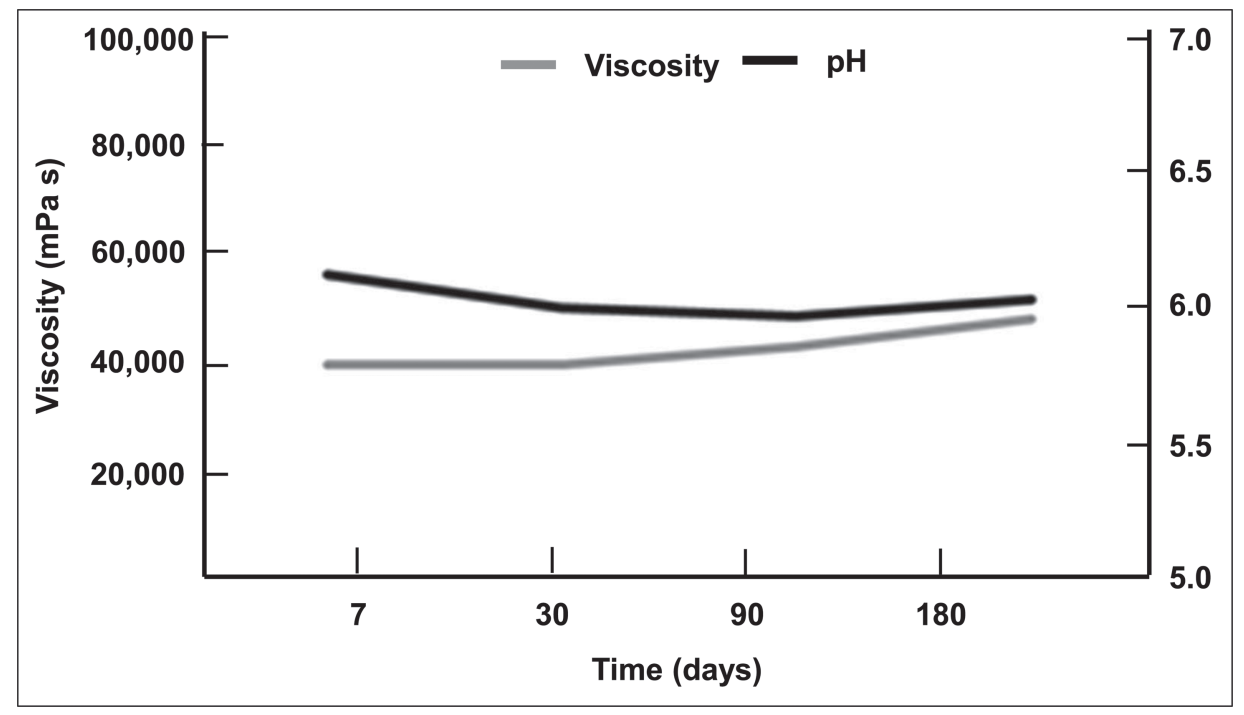

Figure 4 Viscosity and $p H$ of test formulation as a function of time. 
Table 2 Transepidermal water loss (TEWL) values obtained from skin within each diffusion cell before application of test formulation. Values presented as average \pm standard deviation.

\begin{tabular}{|c|c|c|c|c|c|c|c|c|}
\hline \multirow{2}{*}{$\begin{array}{c}\text { EWW } \\
\left(\boldsymbol{g ~}^{-2} \boldsymbol{h}^{-1}\right)\end{array}$} & Cell 1 & Cell 2 & Cell 3 & Cell 4 & Cell 5 & Cell 6 & Cell 7 & Cell 8 \\
\cline { 2 - 8 } & $14 \pm 1.2$ & $3.6 \pm 0.9$ & $11.9 \pm 4.2$ & $13.9 \pm 4.1$ & $6.8 \pm 2.8$ & $4.0 \pm 3.2$ & $11.9 \pm 2.5$ & $11.5 \pm 1.2$ \\
\hline
\end{tabular}

After an initial visual observation of the skin pieces, TEWL rates were recorded from the skin surface in each diffusion cell (Table 2). The rate of percutaneous penetration and TEWL would be greatly increased if the barrier function of the SC was compromised. Thus, TEWL was measured before starting the experiment. All TEWL values were less than $15 \mathrm{~g} \mathrm{~m}^{-2} \mathrm{~h}^{-1}$, indicating that the pig-skin samples used in the subsequent test were structurally viable.

Initial dermal absorption studies were performed with test emulsions containing $0.5 \% \mathrm{w} / \mathrm{w}$ PRA and $0.375 \% \mathrm{w} / \mathrm{w}$ ALN. These studies showed that the amounts of active ingredients that pass through the skin after 1, 3, 8 and 24 hours were low and are therefore difficult to measure: many samples contained amounts of drug that were below the limit of detection for the analytical method. This low transdermal flux can be attributed to the finite dose of product deposited on the skin surface. Indeed, the concentration used was well below the saturated concentration usually used for this type of experiment (approximately 500 times lower for PRA and approximately 100 times lower for ALN). Therefore, we opted for a single determination of percutaneous absorption after 24 hours rather than a kinetic study (involving multiple samples of receptor chamber fluid). Skin absorption after $24 \mathrm{~h}$ allowed us to verify whether these low concentrations of drugs penetrated the skin layers in significant quantities.

The Scientific Committee on Consumer Safety requires that the mass balance recovery must be in the range of $85-115 \%$ of the applied dose [19]. The total recovery of PRA exceeded $85 \%$ (Table 3 and Figure 5). The absorbed dose (equivalent to PRA found in the receptor chamber fluid) was $12.1 \%$, with the amount of PRA found in viable skin $(6.6 \%)$ being taken as the potentially absorbed dose. The amount retained by the SC $(34.7 \%)$ was not considered to be dermally absorbed and thus did not contribute to the systemic dose. Thus overall, the percutaneous penetration of PRA was low and the majority of the drug remained on the surface or in the SC. These results are in agreement with the predicted transdermal delivery described earlier.

The total ALN recovered was much less than $85 \%$ (Table 3 and Figure 6). More than 40 $\%$ of the ALN was unaccounted for and under these conditions it is difficult to determine the percutaneous penetration of ALN. Nevertheless, the results show that ALN was found in viable skin and receptor fluid, so ALN penetrates the various skin layers. The reliability of the analytical method was verified by checking the specificity and repeatability parameters. Moreover, all low-concentration dosages were tested with reference to a range of standards. 
Table 3 Quantities of sodium pravastatin (PRA) and sodium alendronate (ALN) recovered after 24 hours, expressed as percentage of applied dose. Values represent average \pm standard deviation.

\begin{tabular}{|c|c|c|c|c|c|}
\hline $\begin{array}{c}\text { Drug Recovery } \\
\text { \% Applied Dose) }\end{array}$ & $\begin{array}{c}\text { Recovery of } \\
\text { formulation }\end{array}$ & $\begin{array}{c}\text { Stratum } \\
\text { corneum }\end{array}$ & $\begin{array}{c}\text { Epidermis }+ \\
\text { dermis }\end{array}$ & $\begin{array}{c}\text { Receptor } \\
\text { fluid }\end{array}$ & TOTAL \\
\hline PRA & $35.1 \pm 8.9$ & $34.7 \pm 9.0$ & $6.6 \pm 1.6$ & $12.1 \pm 8.2$ & $88.5 \pm 27.7$ \\
\hline ALN & $30.9 \pm 11.9$ & $14.9 \pm 2.7$ & $4.9 \pm 1.1$ & $5.9 \pm 4.5$ & $56.6 \pm 20.2$ \\
\hline
\end{tabular}

The entire residual formulation added to the donor compartment at the end of $24 \mathrm{~h}$ was recovered at the end of the study. Given the apparent loss of ALN in the dose recovery, we hypothesised that some ALN evaporated or degraded under the experimental conditions. To test this hypothesis, we added a defined quantity of donor formulation to three cups, sealed them with Parafilm ${ }^{\circledR}$ and placed them in a thermostatic chamber at $32{ }^{\circ} \mathrm{C}$ for $24 \mathrm{~h}$. The cups and Parafilms ${ }^{\circledR}$ were rinsed with extraction solvent after 24 hours and the rinse samples were analysed. The Parafilm ${ }^{\circledR}$ did not contain ALN, so ALN did not evaporate. In addition, the total amount of ALN added to the cup was recovered, so ALN does not degrade under the test conditions after 24 hours.

Collectively, these data suggest that the unrecovered dose may have permeated the skin but was undetected due to strong interactions of the drugs with molecules present in the skin. For example, it is known that bisphosphonates such as ALN strongly chelate multivalent ions [48] and so ALN may have formed insoluble $\mathrm{Ca}^{2+}$ complexes in the skin. Moreover, bisphosphonates are known to bind plasma proteins such as albumin $[49,50]$. Thus, there is a strong possibility that ALN binds skin proteins such as keratin, collagen and elastin. However, we did not explore this issue further in this study. Due to its high water solubility, ALN is not likely to be metabolised in the body [49, 50].

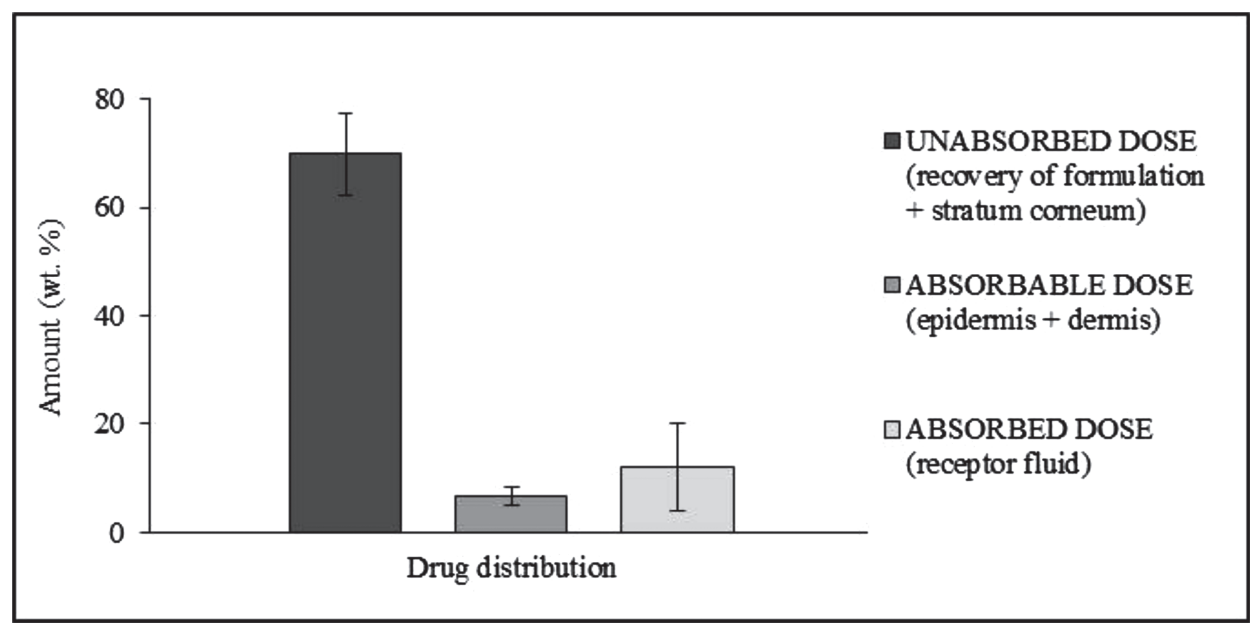

Figure 5 Skin distribution of sodium pravastatin (PRA) after 24 hours, expressed as percentage of applied dose. Values represent average \pm standard deviation. 


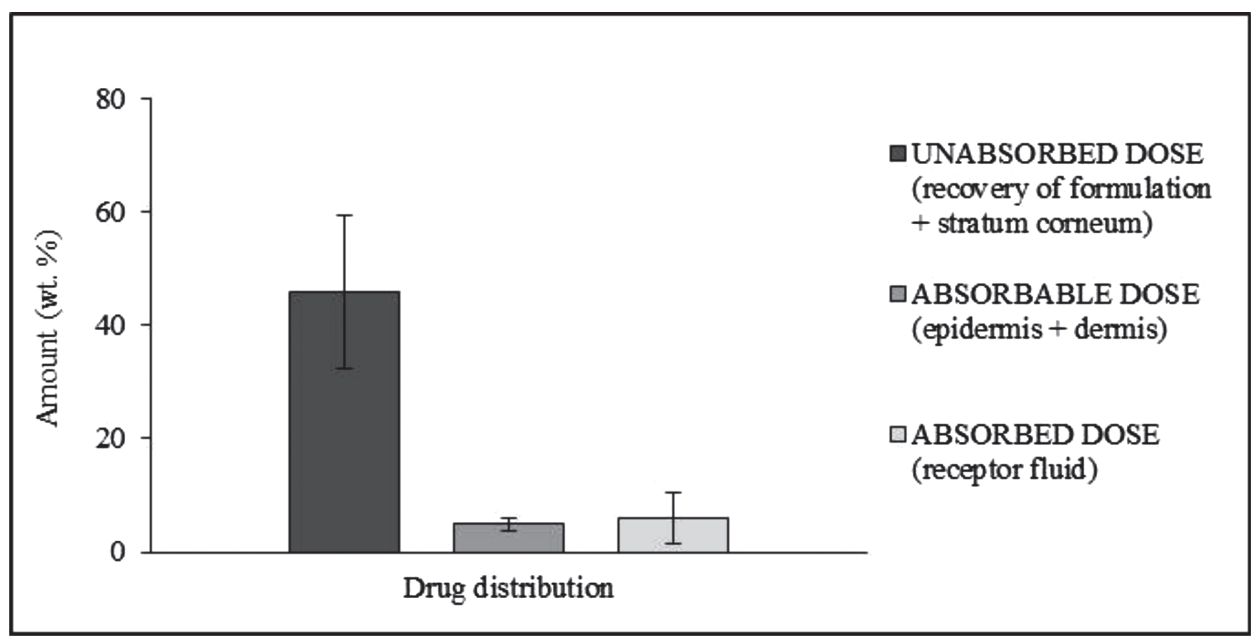

Figure 6 Skin distribution of sodium alendronate (ALN) after 24 hours, expressed as percentage of applied dose. Values represent average \pm standard deviation.

In order to perform a safety assessment, the Systemic Exposure Dosage (SED) was estimated using Equation 1 which takes into account the skin surface intended for treatment with the product as well as the frequency of product application and its retention factor $[19,20,51]$.

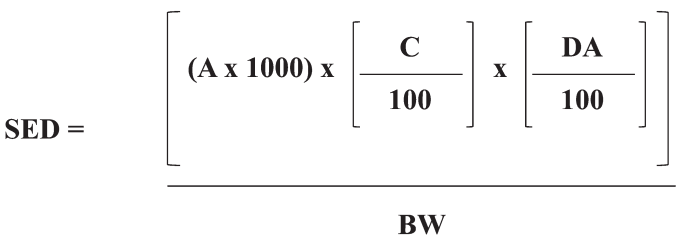

Where SED is the Systemic Exposure Dose (expressed as $\left.\mathrm{mg} \mathrm{kg}^{-1} \mathrm{day}^{-1}\right), \mathrm{A}\left(\mathrm{g} \mathrm{day}^{-1}\right)$ is the amount of finished product applied (generally assumed to be $800 \mathrm{mg}$ for a single facial application), $\mathrm{C}$ is the concentration (\%) of the active ingredient, DA is the dermal absorption (expressed as percentage of applied dose) and BW is body weight (default $=60$ $\mathrm{kg})$.

The experimental value for DA was derived from the in vitro permeability study and represents the amount of active ingredient recovered in the epidermis, dermis and receptor fluid. The value of DA used for the calculation was based on the average (18.7) plus two standard deviations (17.6) to give an assumed dose of $36.3 \%$ (Table 4) to incorporate a margin of safety [19]. Given the poor recovery of ALN, its concentration in the final product was considered to be entirely absorbed $(\mathrm{DA}=100 \%)$ for the SED calculation [19]. 
Table 4 Dermal absorption of sodium pravastatin (PRA) and sodium alendronate (ALN) expressed sum of \{absorbed and absorbable\} percentage of applied dose derived from (I) experimental measurements and (II) assumed for the purpose of calculating the SED (systemic exposure dose; Equation 1).

\begin{tabular}{|c|c|c|c|}
\hline \multirow{2}{*}{ Drug } & \multicolumn{2}{|c|}{$\begin{array}{c}\text { Dermal Absorption } \\
\text { (DA; \% applied Dose) }\end{array}$} & \multirow{2}{*}{$\begin{array}{c}\text { Calculated SED } \\
\text { (mg kg }^{-1} \text { day }^{-1} \text { ) }\end{array}$} \\
\cline { 2 - 4 } & (I) Experimental & (II) Assumed & 0.027 \\
\hline PRA & $18.7 \pm 8.8$ & 36.3 & 0.52 \\
\hline ALN & $10.8 \pm 4.6$ & 100 & \\
\hline
\end{tabular}

It is generally accepted that the Margin of Safety (MoS) of a substance can be calculated by dividing its lowest No Observable Adverse Effect Level (NOAEL) value by its calculated SED. The selection of endpoints for NOAELs is difficult but critical because these numbers are often used by risk assessors. Selecting the most appropriate endpoint is fundamental, but only two relevant studies have been published for PRA and only one for ALN. Table 5 therefore provides only an estimate of the MoS; these conclusions should be modified with an extended analysis of the literature on repeated exposure tests for PRA and ALN.

Based on studies in dogs using the oral route of administration, the lowest NOAEL was reported to be $25 \mathrm{mg} \mathrm{kg}^{-1}$ day $^{-1}$ for PRA [52 - 54] and $2 \mathrm{mg} \mathrm{kg}^{-1} \mathrm{day}^{-1}$ for ALN [37]. Factoring in a safety margin of 10 to cover inter-species differences and an additional factor of 10 to cover inter-individual differences, the acceptable MoS should be $>100$ [51].

In the future, the amount of ALN in the formulation can be decreased, and the MoS can be increased to obtain an acceptable safety margin for ALN. It is also possible to improve the test performance to obtain a usable DA value that does not consider the starting ALN concentration and thereby increases the MoS.

\section{CONCLUSIONS}

A synergistic combination of two anti-aging active ingredients (PRA and ALN) was incorporated into an oil-in-water emulsion with the required cosmetic characteristics for topical application. An in vitro permeability study using this cosmeceutical vehicle

Table 5 Calculated margins of safety (MoS) for sodium pravastatin (PRA) and sodium alendronate $(A L N)$ derived from experimental measurements of dermal absorption and reported no observable adverse effect level (NOAEL).

\begin{tabular}{|c|c|c|c|}
\hline Drug & $\begin{array}{c}\text { NOAEL } \\
\left(\mathbf{m g ~ k g}^{-1} \mathbf{d a y}^{-1}\right)\end{array}$ & Species and route of administration & MoS \\
\hline PRA & 25 & Dog, oral [52-54] & 926 \\
\hline ALN & 2 & Dog, oral [32] & 3.8 \\
\hline
\end{tabular}


demonstrated that both molecules are able to diffuse through the skin barrier into the dermis in small amounts despite their high hydrophilicity and strong ionisation.

These results provide evidence to support clinical studies demonstrating the in vivo efficiency of the PRA/ALN combination to ameliorate the signs of skin aging, although the concentrations of PRA and ALN in the product must first be optimised. To satisfy to required safety criteria for cosmetics (i.e., an MoS > 100) the ALN concentration should be reduced and the relative quantity of the two drugs should be adjusted to account for their different skin permeation properties.

This study provides preliminary data for the development of a new anti-aging transdermal delivery system.

\section{ACKNOWLEDGEMENTS}

We wish to thank the slaughterhouse (Pézenas, France) for kindly donating the pig ears. The authors are grateful to David Bergé-Lefranc for his expertise in physical chemistry. Finally, we thank Pierre Cau for his assistance in laminopathy.

\section{REFERENCES}

1. M. A. Farage, K. W. Miller and H. I. Maibach, Degenerative changes in aging skin, in Textbook of Aging Skin, ed. M. A. Farage, K. W. Miller and H. I. Maibach, 2010, Springer, Berlin, pp. 25-35.

2. J. K. Rivers, The role of cosmeceuticals in antianging therapy, Skin Therapy Lett, 2008, 13(8), 5-9.

3. M. Amer and M. Maged, Cosmeceuticals versus pharmaceuticals, Clin Dermatol, 2009, 27(5), 428-30.

4. F. S. Brandt, A. Cazzaniga and M. Hann, Cosmeceuticals: current trends and market analysis, Semin Cutan Med Surg, 2011, 30(3), 141-3.

5. R. C. Hennekam, Hutchinson-Gilford progeria syndrome: review of the phenotype, Am J Med Genet A, 2006, 140(23), 2603-24.

6. M. A. Merideth et al., Phenotype and course of Hutchinson-Gilford progeria syndrome, N Engl J Med, 2008, 358(6), 592-604.

7. A. De Sandre-Giovannoli et al., Lamin a truncation in Hutchinson-Gilford progeria, Science, 2003, 300(5628), 2055.

8. M. Eriksson et al., Recurrent de novo point mutations in lamin A cause HutchinsonGilford progeria syndrome, Nature, 2003, 423(6937), 293-8.

9. C. L. Navarro, P. Cau and N. Levy, Molecular bases of progeroid syndromes, Hum Mol Genet, 2006, 15 Spec No 2, R151-61. 
10. P. Scaffidi and T. Misteli, Science, 2006, 312, 1059-1063.

11. J. Espada et al., Nuclear envelope defects cause stem cell dysfunction in prematureaging mice, $J$ Cell Biol, 2008, 181(1), 27-35.

12. P. Scaffidi and T. Misteli, Nat Cell Biol, 2008, 10, 452-459.

13. I Varela et al., Combined treatment with statins and aminobisphosphonates extends longevity in a mouse model of human premature aging, Nat Med, 2008, 14(7), 767-72.

14. LIMP, Effet de 4 compositions cosmétiques sur la division de ficroblastes humains agés et jeunes sur 72H, 2008.

15. L. E. Millikan, Cosmetology, cosmetics, cosmeceuticals: definitions and regulations, Clin Dermatol, 2001, 19(4), 371-4.

16. R. O. Potts and R.H. Guy, Predicting skin permeability, Pharm Res, 1992, 9(5), 663-9.

17. L. Duracher et al., The influence of alcohol, propylene glycol and 1,2-pentanediol on the permeability of hydrophilic model drug through excised pig skin, Int $J$ Pharm, 2009, 374(1-2), 39-45.

18. T. J. Franz, Percutaneous absorption. Relevance of in vitro data, J. Invest. Dermatol, 1975, 64, 190-195.

19. SCCS, Basic criteria for the in vitro assessment of dermal absorption of cosmetic ingredients, in SCCS/1358/10, 2010, European Commission, Brussels.

20. OECD, Guideline for the Testing of Chemicals. Skin absorption: In vitro method., in Draft Guideline 428, 2000, OECD, Belgium.

21. G. A. Simon and H. I. Maibach, The pig as an experimental animal model of percutaneous permeation in man: qualitative and quantitative observations--an overview, Skin Pharmacol Appl Skin Physiol, 2000, 13(5), 229-34.

22. A. Nangia et al., In vitro measurement of transepidermal water loss: a rapid alternative to tritiated water permeation for assessing skin barrier function, Int J Pharm, 1998, 170, $33-40$.

23. C. Fernandez et al., LC analysis of benzophenone-3 in pigskin and in saline solution: application to determination of in vitro skin penetration, J Pharm Biomed Anal, 2000, 22(2), 393-402.

24. L. Duracher et al., Irradiation of skin and contrasting effects on absorption of hydrophilic and lipophilic compounds, Photochem Photobiol, 2009, 85(6), 1459-67.

25. E. Kurul and S. Hekimoglu, Skin permeation of two different benzophenone derivatives from various vehicles, Int J Cosmet Sci, 2001, 23(4), 211-8.

26. P. Clarys et al., There is no influence of a temperature rise on in vivo adsorption of UV filters into the stratum corneum, J Dermatol Sci, 2001, 27(2), 77-81. 
27. J. D. Bos and M. M. Meinardi, The 500 Dalton rule for the skin penetration of chemical compounds and drugs, Exp Dermatol, 2000, 9(3), 165-9.

28. A. Naik, Y. N. Kalia and R. H. Guy, Transdermal drug delivery: overcoming the skin's barrier function, Pharm Sci Technolo Today, 2000, 3(9), 318-326.

29. B. M. Magnusson et al., Molecular size as the main determinant of solute maximum flux across the skin, $J$ Invest Dermatol, 2004, 122(4), 993-9.

30. M. Schneider et al., Nanoparticles and their interactions with the dermal barrier, Dermatoendocrinol, 2009, 1(4), 197-206.

31. B. M. S. Company, Princeton, New Jersey, 08543, USA.

32. EMEA, Scientific discussion - Fosavance, 2005.

33. H. N. Joshi, M. G. Fakes and A. T. Serajuddin, Differentiation of 3-Hydroxy3methylglutaryl-coenzyme A Reductase Inhibitors by their Relative Lipophilicity, Pharm Phamacol Commun, 1999, 5, 269-271.

34. EDQM, Safety data sheet sodium alendronate, 2008.

35. I. Tamai et al., Proton-cotransport of pravastatin across intestinal brush-border membrane, Pharm Res, 1995, 12(11), 1727-32.

36. M. Meloun et al., Thermodynamic dissociation constants of alendronate and ibandronate by regression analysis of potentiometric data, J Chem Eng, 2011, 56, 3848-3854.

37. J. Hadgraft and W. J. Pugh, The selection and design of topical and transdermal agents: a review, J Investig Dermatol Symp Proc, 1998, 3(2), 131-5.

38. A. Alikhan, S. Farahmand and H. I. Maibach, Correlating percutaneous absorption with physicochemical parameters in vivo in man: agricultural, steroid, and other organic compounds, J Appl Toxicol, 2009, 29, 590-596.

39. M. S. Roberts, W. J. Pugh and J. Hadgraft, Epidermal permeability: penetrant structure relationships. 2. The effect of H-bonding groups in penetrants on their diffusion through the stratum corneum, Int J Pharm, 1996, 132, 23-32.

40. J. du Plessis et al., Physico-chemical determinants of dermal drug delivery: effects of the number and substitution pattern of polar groups, Eur J Pharm Sci, 2002, 16(3), $107-12$.

41. M. S. Roberts, S. E. Cross and M. A. Pellet, Skin transport, in Dermatological and transdermal Formulations, ed. A. W. Walters, 2002, Marcel Dekker, New York.

42. Y. Garg and K. Pathak, Design and in vitro performance evaluation of purified microparticles of pravastatin sodium for intestinal delivery, Pharm Sci Tech, 2011. 12(2), 673-82. 
43. M. E. Lane et al., Passive Skin Permeation Enhancement, in Topical and Transdermal Drug Delivery: Principles and Practice, ed. H. A. E. Benson and A. C. Watkinson, 2012, Wiley, pp. 23-42.

44. W. J. Pugh, I. T. Degim and J. Hadgraft, Epidermal permeability-penetrant structure relationships: 4, QSAR of permeant diffusion across human stratum corneum in terms of molecular weight, H-bonding and electronic charge, Int J Pharm, 2000, 197(1-2), 203-11.

45. D. Karadzovska et al., Predicting skin permeability from complex vehicles, Adv Drug Deliv Rev, 2012.

46. M. S. Robert and M. Walker, Water: the most natural penetration enhancer., in Pharmaceutical skin penetration enhancement, ed. K. Walter and J. Hadgraft, 1993, New York, pp. 1-30.

47. J. W. Wiechers, The barrier function of the skin in relation to percutaneous absorption of drugs, Pharm Weekbl Sci, 1989, 11(6), 185-98.

48. A. G. Porras and B. J. Gertz, Pharmacokinetics and Pharmacodynamics of Alendronate Development, in Applications of Pharmacokinetic Principles in Drug Development, ed. R. Krishna, 2003, pp. 464-465.

49. J. H. Lin, Bisphosphonates: a review of their pharmacokinetic properties, Bone, 1996, $\mathbf{1 8}(2), 75-85$.

50. F. Karamustafa and N. Celebi, Bisphosphonates and Alendronate, J Pharm Sci, 2006, 31, 31-42.

51. SCCP, Opinion for basic criteria for the in vitro assessment of dermal absorption of cosmetic ingredients, in SCCP/0970/06, 2006, European Commission: Brussels.

52. S. Manabe, et al., Preliminary dose finding study for subacute toxicological study of pravastatin sodium in monkeys, J Toxicol Sci, 1989, 14 Suppl 1, 41-55.

53. S. Manabe et al., Subacute toxicological study in monkeys treated orally with pravastatin sodium for 5 weeks, J Toxicol Sci, 1989, 14 Suppl 1, 57-83.

54. C. Tarumi et al., Long term oral administration study of pravastatin sodium to beagles for 104 weeks, J Toxicol Sci, 1989, 14 Suppl 1, 85-101. 
